\title{
História, memória e ficção em textos e contextos africanos: notas sobre Moçambique
}

Rita Chaves ${ }^{1}$

Resumo: 0 presente artigo tem como objetivo discutir a relação entre História, memória e ficção em textos e contextos africanos. Levando em conta que, sobretudo em países identificados com a pressão colonial, o apelo ao testemunho e a diversas formas de narrativa possibilita assomarem-se vozes até então silenciadas, questionar a impenetrabilidade do debate informado pelos autores da dominação e sua conservação do monopólio do discurso e do direcionamento de análise, bem como o poder indiscutível dos documentos como fonte de verdade. Daí a importância da integração de outras narrativas cujos procedimentos são associados ao território da memória e dos seus campos de subjetividade, sem desconsiderar os riscos desse recurso. Portanto, devido ao itinerário histórico de alguns países, a exemplo de Moçambique e Angola, precisam-se de outros modos de lidar com as linhas da memória. 0 papel da ficção expressa-se como recurso a um instrumento de análise diferente daqueles com que lidamos com mais frequência. Nesse sentido, estabelece-se, a partir da literatura, um papel no processo de formação da identidade nacional, de interpretação do país, interferindo no coro que canta a grande narrativa e fornecendo instrumentos que permitem olhá-lo mais profundamente.

Palavras-chave: História, memória, ficção, subjetividade, Moçambique.

1 Professora de Literaturas Africanas de Língua Portuguesa na Faculdade de Filosofia, Letras e Ciências Humanas da Universidade de São Paulo (USP). 


\title{
HISTORY, MEMORY AND FICTION IN AFRICAN TEXTS AND CONTEXTS: NOTES ON MOZAMBIQUE
}

\begin{abstract}
This article aims to discuss the relationship between history, memory and fiction in African texts and contexts. Taking into account that, especially in countries identified with colonial pressure, the call for testimony and various forms of narrative makes it possible the voices silenced until then to be heard, to question the impenetrability of the debate informed by the authors of domination and its conservation of the monopoly of discourse and of the direction of analysis, as well as the indisputable power of documents as a source of truth. Hence the importance of integrating other narratives whose procedures are associated with the territory of memory and its fields of subjectivity, without disregarding the risks of this resource. Therefore, due to the historical itinerary of some countries, such as Mozambique and Angola, other ways of dealing with the lines of memory are needed. The role of fiction is expressed as a resource to an analysis tool different from those we deal with more frequently. In this sense, a role is established from the literature in the process of formation of national identity, of interpretation of the country, interfering in the chorus that sings the great narrative and providing instruments that allow us to look at it more deeply.
\end{abstract}

Keywords: History, Memory, Fiction, Subjectivity, Mozambique.

"O tempo é um tecido invisível em que se pode bordar tudo: uma flor, um pássaro, uma dama, um castelo, um túmulo. Também se pode bordar nada. Nada em cima do invisível é a mais sutil obra deste mundo, e acaso do outro."

(Machado de Assis)

Entre os temas que têm mobilizado a atenção de muitos estudiosos da contemporaneidade, encontramos a intrincada rede de conexões entre História, memória e ficção e a sua viva repercussão nas formas de abordagem com que nos aproximamos de algumas situações, sobretudo daquelas que reclamam mais legitimamente pela interdisciplinaridade como método. No campo da História, o forte apelo do testemunho como um instrumento de investigação da realidade de algumas décadas para 
cá interferiu no quadro analítico, relativizando a força das fontes primárias e colocando em causa o poder indiscutível dos documentos como fonte de verdade. No terreno da teoria literária, as narrativas de testemunho provocaram também a necessidade de outras perspectivas de leitura que envolviam o ético e o estético, gerando novos conceitos. 0 debate em torno das relações entre o romance autobiográfico e a autoficção movimentaram o cenário intelectual francês na década de 1970, com ecos que se desdobram em nosso presente.

Sobretudo nos contextos identificados com a pressão colonial, o testemunho converteu-se em um gênero cultivado, oferecendo um material produtivo para questionar a impenetrabilidade do debate informado pelos atores da dominação, dando continuidade, guardadas as devidas diferenças, ao movimento que teve como tema fundamental o holocausto e o lugar destinado a suas vítimas. Embora não possam ser apontados como marcos fundadores de uma prática de terror, uma vez que a existência dos campos de concentração está inscrita na vida de outros povos, lugares como Auschwitz, Sobibor e Treblinka tornaram-se ícones de uma história que era preciso não esquecer, história que foi legitimada pelo poder da escrita e da imagem insistentemente difundida pelo cinema. Décadas após a Segunda Grande Guerra, a profusão de testemunhos sobre os horrores contra os judeus dividiria o espaço com a denúncia de outro tipo de violência, aquela que recaía sobre os deserdados pela exploração econômica e pelos abusos políticos. Entraram em cena livros como Si me permiten hablar, que retrata a vida de Domitila Barrios de Chungara (1937-2012), registrando-a em enfrentamento com a ditadura militar na Bolívia, nos anos 1970. Mais tarde, os tempos de pós-ditadura na América do Sul enfatizaram o papel dos protagonistas da resistência, acolhendo com entusiasmo o coro das vozes que tinham sido banidas pela tenebrosa opressão que conheceu seu auge na tristemente célebre Operação Condor, a qual dominou o Cone Sul do nosso continente.

A emergência das narrativas, em que assomam vozes até então silenciadas, possibilitou, sem dúvida, um contrabalanço da hegemonia de classe que durante séculos soube conservar o monopólio dos discursos e direcionar as análises. A despeito do esforço investido pelo discurso historiográfico na racionalização das fontes e dos repertórios trazidos pela memória, como recorda Fernando Rosas, "essa busca nunca deixou 
de ser condicionada política e ideologicamente pelo ser social de seu autor, pelo caldo político e cultural onde este mergulha" ${ }^{2}$. A voz que se eleva com a chegada ao palco desses novos protagonistas também concorre para reforçar alguns novos rumos trilhados pela História e pelas Ciências Sociais, incorporando métodos e fontes que colocam em causa a irredutibilidade de certas posições. Enzo Traverso, analisando a relação entre memória, história e marxismo, enfatiza o "moment memoriel" de meados dos anos 1980 nas sociedades ocidentais, época da publicação do primeiro volume de Les lieux de mémoire, de Pierre Nora, na França; de Zakhor: história judaica e memória judaica, de Yosef Hayim Yerushalmi, nos Estados Unidos da América; de Os afogados e os sobreviventes, de Primo Levi, na Itália; de Shoah, de Claude Lanzmann, filme centrado exclusivamente nas lembranças das vítimas ${ }^{3}$. Em certa medida, podemos incluir nesse quadro a valorização da história oral como expressão dessa experiência conduzida pela necessidade de dinamização de outros pontos de vista, o que significou obviamente a aproximação com procedimentos associados ao território da memória e dos seus campos de subjetividade. Com os riscos aí inseridos e as dificuldades que os planos subjetivos trazem à reflexão, a decorrente integração de outras narrativas e os novos modos de atualizá-las levaram a uma frutuosa verticalização do debate epistemológico que a contemporaneidade reclamava.

A situação da América Latina, com seu longo passado colonial, foi um terreno fértil para essa concorrência entre o rio da História e os caudais da Memória, gerando um repertório que, temperado pela ficção, assegurara referências instigantes para o balanço de um processo dividido pelas tensões entre a autoridade do ocupante e as formas de resistência do ocupado. $\mathrm{Na}$ análise de Antonio Candido, no processo de conhecimento do próprio país, a compensação do "atraso material e a debilidade das instituições"4 imputava à literatura um papel substitutivo e é exemplar como no Brasil do século XIX a narrativa literária irrompe,

2 ROSAS, Fernando. História e memória. Lisboa: Tinta da China, 2016. p. 55.

3 TRAVERSO, Enzo. Melancolia de esquerda: marxismo, história e memória. Belo Horizonte-Veneza: a/Editora Âyiné, 2018. p. 137-138.

4 CANDIDO, Antonio. Formação da literatura brasileira: Momentos decisivos. 6. ed. Belo Horizonte: Itatiaia, 1981. p. 141. 
acrescentando elementos para a composição de um conhecimento mais efetivo e diversificado da nação. Procurando captar dados históricos e geográficos do país recém-independente, a vida literária se instala, investindo na proposta regionalista com que se procurava reconhecer o país em sua diversidade. Na verdade, estava em curso o desejo de inventar a nação a partir da afirmação de uma importante dimensão simbólica. A obra que se manifesta nos romances de amplitude variada de Alencar é certamente o sinal mais significativo. No confronto entre invasores e invadidos, situa-se uma espécie de arena que abriga novos pontos de disputa a partir dos quais afirmam-se novos símbolos do estado nacional, ainda que no nosso caso a conciliação tenha sido um elemento forte na equação que se desenhou e se mantém.

Se nos deslocamos para o outro lado do Atlântico, o desembarque em terras africanas leva-nos a outros e instigantes cenários. 0 processo colonial, mais longo e acidentado, vai nos trazer elementos para uma discussão que chega ao presente e nos revela a complexidade dessa ligação entre memória, história e ficção até os nossos dias. Recortada por processos específicos, que, nascendo com a invasão colonial, não foram equacionados pelas independências (elas próprias, muitas vezes, caracterizadas por novas crises de instabilidade e convulsões de várias ordens), a África tem sido palco de situações que convidam a exames capazes de mergulhar no emaranhado de fios que compõem e representam o seu passado e deságuam em seu presente. A particularidade de suas experiências, caracterizadas por uma dose de violência ainda mais intensa e prolongada do que a vivida em outras invasões, impõe a necessidade de configurar outros conceitos e paradigmas, procedimento essencial para evitar o vício de mecanicamente aplicar o que foi pensado para conhecer outros territórios e situações. Assim, a inserção de certos aportes da História em sua nova maneira de lidar com as linhas da Memória mostrase ali especialmente fecunda para a escavação de camadas ainda pouco revolvidas na fermentação do conhecimento. Do mesmo modo, o papel da ficção merece a argúcia e o cuidado do nosso olhar.

A fim de fugir do perigo das generalizações, podemos fechar o foco em países como Angola e Moçambique, por exemplo, que há apenas quatro décadas e meia puseram fim à ocupação colonial, e observar como é difícil divisar as fronteiras entre a memória e a história, e como são fundos os 
sobressaltos inerentes a um percurso complicado, muitas vezes coberto com mais profundidade pelas linhas sinuosas da ficção. Em ambos os casos, estamos diante de cenários tocados por forte instabilidade, envolvendo intensos conflitos sociais e políticos, em que o jogo entre as velhas e as novas relações de poder se insinua ou se explicita e torna as tensões entre a ordem passada e a atual constitutivas desse presente marcado por muitas variáveis. Em outras palavras, certos contextos africanos revelam mais fortemente uma espécie de rede de fios soltos com que nos deparamos em face do itinerário histórico de alguns países, o que impõe, muitas vezes, o recurso a instrumentos de análise diferentes daqueles com que lidamos com mais frequência.

Sob vários aspectos, somam-se os problemas que explicam a dificuldade de conhecimento da história nesses territórios. Em artigo recentemente publicado, João Paulos Borges Coelho identifica como um primeiro grande problema para a fragilidade de uma historiografia em Moçambique a sua própria escassez, indicando causas muito concretas para essa débil tradição que, naturalmente, tem raízes na sociedade colonial:

Tal situação, ao menos em parte, deve-se a uma herança colonial de difícil acesso da maioria da população a algo mais do que o nível básico de ensino, em particular à ausência quase absoluta de africanos no ensino superior no tempo colonial; a isto poderíamos associar a inexistência de cursos universitários de história até às vésperas da independência ${ }^{5}$.

De fato, o tempo e as condições da própria independência moçambicana deixaram o país em descompasso em relação a outros países africanos, em que, nos anos 1950 e 1960, com os processos de descolonização, a disciplina ganhou alguma relevância, empenhando-se para rebater a "ideia de um continente sem história, onde o africano passa de objeto a sujeito da história e onde ainda a narrativa nacionalista assume

COELHO, João Paulo Borges. Política e história contemporânea em Moçambique: dez notas epistemológicas. Revista de História, São Paulo, n. 178, p. 1, 2019. Disponível em: http://dx.doi.org/10.11606/issn.2316-9141.rh.2019.146896. Acesso em: 5 ago. 2020. 
um lugar privilegiado" ${ }^{\prime \prime}$. Sem se ter beneficiado desses ventos favoráveis, 0 desenvolvimento da história de Moçambique é atingido pelo desprestígio da disciplina em tempos de dominância neoliberal, como menciona Borges Coelho, e padece ainda da presença rarefeita de vozes locais na constituição de um discurso sobre a sua própria trajetória em função de obstáculos impostos à reflexão por condicionamentos materiais, e não só. A despeito das transformações já verificadas, enredados nos laços da captura, da predação e da exploração, que constituem o campo semântico do sistema colonial, os africanos, de modo geral, ainda enfrentam sérias limitações na formulação de ideias sobre o que viviam e vivem. 0 acesso à escrita no século XVIII minimizou a tragédia do silenciamento ${ }^{7}$, mas a participação na reflexão ainda conhece restrições e continua coibindo a saudável interlocução tão necessária ao amadurecimento das análises. A centralização do que reconhecemos como hemisfério ocidental e o peso do eurocentrismo daí decorrente são questões à volta das quais pensadores como Edward Saïd e Achille Mbembe têm concentrado sua atenção.

No que se refere a tempos mais remotos, essa escassez também se relaciona à questão dos documentos que compõem o patrimônio do colonizador. De maneira geral, as fontes disponíveis estão associadas ao legado do colonialismo, tendo sido acumuladas e organizadas pelo olhar imperial. A organização das fontes certamente interfere na própria lógica das análises, que tenderam sempre a ver a história de Moçambique e de Angola apenas no âmbito da história da metrópole. Registram-se poucas tentativas de examinar Moçambique sob outros enquadramentos, buscando outros vínculos determinados, algumas vezes, por ligações geográfico-culturais que derivam da sua localização no Oceano Índico e/ou da sua vocação oriental. Do mesmo modo, ainda são poucos os trabalhos que buscam encarar Angola em outros campos relacionais, como o que realizou Luiz Felipe de Alencastro em $O$ trato dos viventes.

6 CRUZ E SILVA, Teresa. Memória, história e narrativa: Os desafios da escrita biográfica no contexto da luta nacionalista em Moçambique. Revista Crítica de Ciências Sociais, n. 106, p. 135, 2015. Disponível em: http://dx.doi.org/10.4000/rccs.5916. Acesso em: 5 ago. 2020.

7 MBEMBE, Achille. Crítica da razão negra. 1. ed. Lisboa: Antígona, 2014. p. 12. 
E como muito bem defende Ruy Duarte de Carvalho, alertando para a necessidade de integrar a história de Angola em um foco mais aberto ${ }^{8}$.

Muito embora o fim do sistema colonial tenha aberto possibilidades para o fortalecimento de um olhar menos comprometido, outros fatores viriam condicionar o trabalho de reflexão e limitar a área de atuação da História e dos historiadores nesses países. Se, por um lado, é possível observar a incorporação de novos temas, mais coerentes com as realidades dos povos que ali habitam, por outro lado, não se pode deixar de notar um problema que tem sido denunciado por muitos estudiosos sobre períodos mais próximos, notadamente ao tempo da luta armada e aos primeiros anos pós-independência. É notória e justificada a reclamação de pesquisadores nacionais e estrangeiros que têm seu trabalho dificultado pela interdição às fontes em função da apropriação dos arquivos pelos partidos que se formaram a partir dos movimentos de libertação, como é o caso da Frente de Libertação de Moçambique.

Podem-se encontrar as razões da recusa em abrir a documentação no quadro complexo em que se formam os processos de libertação e as condições da independência. A dinâmica da empresa colonial portuguesa, recusando-se a negociar com os nacionalistas, condicionou a eclosão da luta armada que levaria à libertação tardia das colônias. A vitória, nesses termos, criou para os movimentos de libertação uma especial concentração de poder, confirmada simbolicamente pela saga que viveram. Conquistada a grande vitória sobre o invasor, os protagonistas do bom combate viram-se ungidos por uma espécie de aura que lhes assegurava um lugar inquestionável na gestão da sociedade que vinham fundar. As sucessivas crises, desdobrando-se em conflitos políticos e sociais, os quais foram geridos com uma impressionante habilidade por esses heróis, acabaram contribuindo para a continuação deles no governo e a forma centralizadora conduziu a uma espécie de simbiose entre o estado nacional e o partido que o havia fundado.

No desenvolvimento desse processo, João Paulo Borges Coelho enxerga a figuração de uma espécie de fábula, isto é, de uma grandenarrativa de estrutura simples e apoiada na força de um binarismo

8 CARVALHO, Ruy Duarte de. Actas da Maianga. Lisboa: Cotovia, 2003. p. 43. 
manifesto no jogo de oposições entre pares, como revolucionários $\times$ reacionários, militares $x$ civis, rural $\times$ urbano. 0 sentido de pureza com que o movimento se tingiu tornava-se uma espécie de selo de garantia e Ihe deu, durante décadas, o estatuto de indiscutível sujeito, com franca possibilidade de decidir sobre o destino do novo estado e de conduzir a nação, desdobrando-se, da gestão do presente, a função de administrar também o plano simbólico que se formava. Como se, pela legitimidade que não se contestava, a eles tivessem também sido concedidos o dever e o direito de administrar todo o processo de representação desse novo tempo, sobretudo no que dizia respeito à luta de libertação que funcionou como a gesta fundadora. O lugar ocupado pela luta armada e pelo seu campo simbólico destacou-se com grande intensidade das outras formas de reação ao colonialismo e ao combate pela independência, instituindose uma mística que deixava em lugar muito secundário todos os outros atores. A energia da vitória e o reconhecido carisma dos guerrilheiros serviam como selo de validação das certezas que o setor hegemônico, dentro da própria FRELIMO, difundia. Em uma palestra proferida em 2015, Luís Bernardo Honwana alerta para as condições em que a independência foi conquistada e avalia a atitude do partido no poder:

Os partidos ou movimentos libertadores assumiram no âmbito da filosofia adoptada pela organização da unidade Africana a tarefa de construir o estado-nação a partir de um facto político - a proclamação do estado num processo que é inverso ao da tradição de o Estado aparecer como consagração política de uma nação latente.

Nestas circunstâncias, o processo vitorioso da libertação nacional ou, melhor dizendo, a sua narrativa, é um capital com que se conta justamente para a construção da nação. Se calhar, o mais importante capital $^{9}$.

Para Honwana, sob essa perspectiva se pode compreender a "utilização defensiva desse capital, incluindo preservá-la enquanto narrativa para o propor como referência comum"10. A compreensão do

9 HONWANA, Luís Bernardo. A velha casa de madeira e zinco. Maputo: Alcance, 2017. p. 125.

10 Ibidem. 
processo não deve afastar, contudo, o espanto causado pela defesa da exclusividade nos moldes em que se observa o fenômeno em Moçambique, sobretudo se o confrontamos, por exemplo, com o caso angolano. Com a independência conquistada também em 1975, e também pela via armada, em uma luta que durou treze anos, Angola apresenta-nos um quadro um pouco diferente. Lá a glorificação dos guerrilheiros não dissolveu a posição de outros participantes do combate revolucionário, aí incluindo os presos políticos e os que lutavam no exílio, com certo destaque para os escritores e artistas que assumiram a defesa do nacionalismo. A proposta de consciencialização política através da arte e da cultura que havia mobilizado os angolanos, principalmente a partir do fim dos anos 1940, deixara sementes, convertendo as várias formas de arte em um território de construção identitária: no conjunto musical N'gola Ritmos e no grupo teatral Gesto podemos reconhecer alguns dos ícones dessa travessia ${ }^{11}$. E, participando vivamente do processo libertário, os escritores chamaram para si a responsabilidade de compor a imagem de uma nação que se formava. Romances como A vida verdadeira de Domingos Xavier, de José Luandino Viera, e Mayombe, de Pepetela, ambos sobre a luta pela independência, se inscrevem nesse processo de formação da identidade nacional e integram a grande narrativa. Misturado à militância, o ato de escrever definia-se como uma atitude política, o que contribui muito para conferir à atividade literária um forte prestígio. Assim, a literatura angolana é parte ativa no processo de descoberta e interpretação do país, para usar a expressão de Antonio Candido a respeito da ficção brasileira no período romântico. Como parte viva e acalentada pelo novo poder, a literatura ajuda a criar a nação, interferindo no coro que canta a grande narrativa nacional, inclusive como elemento dissonante. Vale a pena recordar o acontecimento envolvendo o citado Mayombe: escrito por um guerrilheiro na guerrilha, que a partir de 1976 ocupa o cargo de vice-ministro da Educação, só teve autorização para ser publicado em 1980. Aqui importa tanto ressaltar o tempo para a sua edição como a sua liberação, tudo a indicar que a unidade não eliminava algumas crises que rondavam aqueles tempos.

1 Sobre o tema, vale a pena assistir ao documentário 0 ritmo do N'gola Ritmos, de António Ole. 
Continuando o paralelo entre as duas ex-colônias lusitanas, podemos identificar outras diferenças que, sem dúvida, se projetam na relação dos poderes que vão gerir os novos estados com a vida literária. Em Angola, o mito fundador da campanha nacionalista está associado à cidade de Luanda e o movimento que declara a independência em 11 de novembro enraizava-se no tecido urbano, fazendo apelo à pluralidade étnica e racial e reclamando uma abertura para o que se podia reconhecer como práticas culturais da modernidade. Era significativo o peso de intelectuais como Agostinho Neto e Mário de Andrade, para ficarmos apenas com dois que ocuparam cargos de direção no Movimento Popular de Libertação de Angola (MPLA), sem nos esquecermos da figura proeminente de Viriato da Cruz, poeta notável, afastado em um dos episódios de ruptura ainda em 1963. A relevância de nomes, como António Jacinto, António Cardoso, Costa Andrade, Luandino Vieira e Pepetela, reflete a composição do movimento e revela uma abordagem em que as marcas urbanas tinham forte ressonância, assegurando um lugar honroso para a literatura enquanto instituição.

Em Moçambique, desenhou-se outro quadro. Não obstante houvesse no mundo literário uma coesão manifesta na rejeição à visão colonial, fenômeno que se afirma também sobretudo a partir dos anos 1940, não se pode falar em uma ligação estrutural entre os escritores e a FRELIMO na condução da luta. O braço urbano do movimento (a chamada IV Região), que se organizara na capital, foi desmantelado em 1965, ainda no começo da guerra de libertação, rompendo-se um elo jamais refeito em profundidade. Entre os companheiros que foram presos (entre os quais podemos citar escritores como José Craveirinha e Rui Nogar e o pintor Malangatana) e os guerrilheiros que estavam na mata, não foi possível recuperar a ligação. No contexto pósıqvo-, localizam-se traços da divisão francamente hierarquizada entre os grupos que combateram em diferentes trincheiras, assim como pode-se observar a presença de um olhar suspeito em relação aos chamados intelectuais, sem devotar qualquer distinção aos escritores e artistas, como sintetiza João Paulo Borges Coelho:

A FRELIMO entrou no país com uma grande desconfiança das cidades e, embora o movimento literário estivesse do lado certo da barricada, 
denunciando o regime colonial e explorando diversas vertentes do nacionalismo, geograficamente estava, todavia, do lado errado ${ }^{12}$.

A fatura desse "erro de localização" foi cobrada ao longo dos anos, exprimindo-se o descompasso em vários episódios que davam notícia da complicada relação entre o Estado e seus representantes e a vida literária. A polêmica gerada pela criação da revista Charrua é um bom exemplo da atmosfera que tingia os laços entre a literatura e o poder institucional, em notório contraste com o que ocorria em Angola, onde a interação e uma certa harmonia dominavam a conexão entre o Estado e os escritores. A rápida fundação da União dos Escritores Angolanos, já no dia 10 de dezembro de 1975, portanto apenas 4 semanas após a independência, e a integração de nomes como o do Presidente Neto demonstram o lugar que a instituição ocuparia nos primeiros anos do novo país. Sagrada e consagrada literariamente, a cidade de Luanda situava-se como um porto de abrigo do movimento nacionalista, refletindo também a composição bastante urbanizada do MPLA. Em Angola, é evidente, a cidade não constituía ameaça e sua imagem, ao contrário, adaptava-se muito bem à ideia de espaço plural que o projeto nacional apresentava como seu, no qual estava previsto um papel imprescindível para a literatura.

A similaridade constituída por alguns pontos de contato entre os dois países em seus itinerários históricos não camuflava as diferenças, que se vão plasmar na relação entre a atividade literária e a política, especialmente no que diz respeito à própria relação com a história e a memória. Enquanto em Angola incentivava-se a partilha na construção do que João Paulo Borges Coelho chama de "roteiro da libertação", isto é, a construção da saga que levou à independência, em Moçambique, o partido no poder, zeloso, reclamava a exclusividade na fabulação, chamando para si a gestão dos mitos fundadores ${ }^{13}$, fato que repercute na presença do romance histórico nos dois sistemas literários. Se em Angola a história, inclusive a do tempo colonial, mas não só, foi visitada

12 COELHO, João Paulo Borges. E depois de Caliban? As histórias e os caminhos da literatura no Moçambique contemporâneo. In: GALVES, C. et al. África-Brasil: caminhos da língua portuguesa. Campinas: Ed. da Unicamp, 2009. p. 63.

13 HONWANA, Luís Bernardo. A velha casa de madeira e zinco. p. 125. 
por autores como Pepetela, Manuel Pedro Pacavira, Arnaldo Santos e José Eduardo Agualusa, em Moçambique o processo começou a ganhar corpo muito mais tarde ${ }^{14}$. Mesmo levando-se em consideração a diferença quantitativa relativamente à força do romance como gênero na literatura angolana, o fenômeno merece atenção.

Interditada em alguma medida à ficção em Moçambique, a história da luta pela independência, como já referimos, também enfrentou dificuldades no campo da pesquisa. 0 zelo do poder governamental estendeu-se ao controle dos documentos relativos ao período, contrariando, inclusive, os dispositivos legais: embora a lei garantisse a abertura da documentação, após anos o acesso permanece restrito. Transformada em partido desde 1977, a FRELIMO assenhorou-se do patrimônio, transformando em propriedade particular o que deveria ser visto como um bem público. E é dramaticamente espantoso que na história de um país em que o combate pela libertação tenha sido acompanhado de uma campanha para quebrar a censura e romper o silêncio se preservem práticas apoiadas na negação do direito ao conhecimento, sobretudo quando a argumentação à volta das questões de segurança perdeu a grande motivação. Detentora do caminho que leva à palavra escrita no presente, confundindo-se com o estado, o partido arroga-se o direito de preservar aquela velha dose de exclusividade para dar os contornos da História.

Nesse contexto em que o poder mantém fechadas as portas a um instigante e necessário material de consulta, chama a atenção o aparecimento de um número significativo de livros que assumem o compromisso de contar a história da formação do estado nacional, começando, naturalmente, pela grande saga da libertação. Escritos predominantemente por aqueles que participaram da luta armada, os relatos, assumindo a narração em primeira pessoa, oferecem-se como provas testemunhais de fatos referidos nos discursos oficiais e/ou difundidos pela força da oralidade. Alguns dos títulos trazem já a força dessa posição, como Participei, por isso testemunho, de Sérgio Vieira, Lutei

14 Vale citar Ualalapi (1986), de Ungulani Ba Ka Khosa, e O olho de Hertzog (2010), de João Paulo Borges Coelho. Nos últimos anos, podemos referir a trilogia As areias do Imperador, de Mia Couto, e Gungunhana (2018), também de Ba Ka Khosa. 
pela Pátria: memórias de um combatente da luta pela libertação nacional, de João Facitela Pelembe, e A minha contribuição para a Independência e Edificação do Estado Moçambicano: memórias de um general da linha da frente, de Salésio Teodoro Nalyambipano. Outros optam pelo traço da sugestão, como Vidas, lugares e tempos, de Joaquim Alberto Chissano, Porquê Sakrani?: memórias de um médico de uma guerrilha esquecida, de Helder Martins, Memórias de um guerrilheiro, de José Phahlane Moiane, e Memórias em voo rasante, de Jacinto Veloso. Ou seja, com a dimensão dada pelo caráter autobiográfico dos volumes que, em alguns, se complementa com a referência à memória presente, em vários títulos vemos indícios de um outro nó nessa conexão com a história que aqui nos interpela, que é a tentativa de fazer a história com o recurso do exercício memorialístico sem que se discuta o peso da subjetividade que toda autobiografia carrega.

Não obstante a convicção hoje francamente incorporada de que a historiografia não se pode defender completamente da aparente isenção do documento ${ }^{15}$, é essencial ter em conta os perigos do uso da memória não como parceira, mas praticamente como substituta da história. Se os documentos não são inocentes (e não o são), como ler as recordações de pessoas claramente comprometidas com os fatos a que desejam conceder foros de verdade? Considerando que muitos dos que assinam essas autobiografias pertencem à elite política do país e que defendem o fechamento dos arquivos, ou pelo menos não se contrapõem a isso, é possível fazer algumas ilações acerca desse verdadeiro boom editorial que tem movimentado o país.

O anúncio da preparação e da publicação de tais obras cujos autores integravam a linhagem dos heróis, o grupo que estivera no centro dos acontecimentos, gerou a expectativa que seria agora facultada aos outros setores da população a partilha de alguns dos segredos que teriam sido desvelados com a abertura dos documentos. No fundo, os futuros leitores desses livros ansiavam por adentrar um território fechado pelo secretismo que caracterizava tanta coisa à volta do nascimento da nação.

15 LE GOFF, J. História e Memória. 7. ed. São Paulo: Ed. da Unicamp, 2013. 
Esperava-se que o manto que tinha sido construído pudesse agora ser visto em seu avesso e em suas fissuras, favorecendo o desvelamento de algumas suspeitas e também a discussão de equívocos que certamente foram cometidos em uma situação tão convulsionada. Nesse caso, a memória poderia abrir hipóteses para uma certa quebra na grande narrativa oficial que procurou moldar a constelação identitária que dominava o céu do país. A surpresa está, no entanto, na quase ausência de surpresas, ou seja, na reiteração de lembranças, de valores e de leituras desse passado no qual se depositara a âncora da redenção que a independência propiciou aos moçambicanos. Nem mesmo os autores que estiveram em altos postos no setor da segurança nacional ousam trazer elementos que permitam equacionar certos enigmas que mobilizaram a atenção dos cidadãos em vários momentos.

Interrompendo as suas rememorações em grande parte em 1975, os autores dispensam-se de examinar os resultados do processo que narram e de avaliar a sua própria participação, oferecendo-nos narrativas em que registram a convicção de seus procedimentos, cuja base estava centrada no desprendimento, na crença na justiça, na capacidade de enfrentar sacrifícios, na generosidade e no patriotismo. Esse rio de bons sentimentos só poderia desaguar no mar da vitória, confirmando-se, de determinado modo, uma visão cristã da História, o que não encontraria coerência no caráter revolucionário da utopia proposta. Ocorre ainda que se o curso das narrativas é cortado em um momento em que sobravam razões para celebrar a conquista, o tempo não parou ali. Como compreender, então, a renúncia à discussão de um processo que passou por crises e mudanças? 0 quadro apresentado tem, de um lado, a insistência na mitologia, que foi o eixo da grande narrativa alimentada pelo discurso oficial do qual eram eles também os redatores, e, do outro, a recusa em pautar os problemas e desvios do projeto, combinação que nos coloca diante de algumas perguntas em torno do sentido a encontrar para esse tipo de escrita. Se pouco acrescentam à crônica factual e se não se dispõem a reavaliar o que já estava registrado, o que pretendem tais relatos? Ou o que pretendem seus autores/protagonistas?

Na motivação confessada, com frequência, destaca-se um sentido de dever. Em Lutei pela pátria, João F. Pelembe sublinha "o objetivo de 
informar o povo moçambicano sobre esta importante epopeia que nos conduziu à independência de Moçambique" e "que a juventude e o povo em geral gostariam e precisam de conhecer"16. Em alguns casos, a decisão teria sido tomada após a insistência de amigos e/ou familiares que, depois de ouvirem em sessões privadas muitas histórias, julgaram importante a partilha do privilégio do relato de algumas experiências, que, sem dúvida, teriam alguma graça e algum interesse para ilustrar a história do país. Essa explicação aparece em alguns prefácios ou em notas introdutórias ${ }^{17}$. Porque não podemos ignorar o significado da passagem do oral para o escrito e do privado para o público, temos que buscar outras razões para esse fenômeno, que é novo no país, provoca um certo impacto e vem sendo alvo de interesse de historiadores moçambicanos empenhados na compreensão do presente de seu país, como Amélia Neves Souto, para quem

Perante todas as transformações da ideologia com a qual se identificaram e com o partido a que pertenceram (e pertencem apesar das transformações que sofre), e por isso fonte de referências, a sua identificação com o presente e o futuro parece não fazer sentido se a história do passado não for recuperada e se não se encontrar uma continuidade, ou mesmo alguma ruptura, mas um elo que faça sentido e que justifique a sua permanência nele. É, no fundo, um trabalho de reconstrução de si mesmo, da sua identidade como protagonistas dessa história onde querem reforçar o seu papel num presente agora alvo de questionamento. A sua identidade exige um elo entre passado-presentefuturo que é necessário não apenas encontrar, mas (re)afirmar ${ }^{18}$.

Para a historiadora, exemplos desse "acerto" com o presente estão nas severas restrições feitas por Jacinto Veloso, ex-ministro da Segurança,

16 PELEMBE, João Facitela. Lutei pela pátria: Memórias de um combatente da luta de libertação nacional. Maputo: Edição do Autor, 2012. p. 15.

17 Encontramos exemplos em Memórias em voo rasante, de Jacinto Veloso; De todos se faz um país, de Óscar Monteiro.

18 SOUTO, Amélia Neves. História, memória e identidade na história da FRELIMO/ Moçambique. Conferência Internacional: os intelectuais africanos face aos desafios do século XXI. Em memória de Ruth First (1925-1982). Anais... Maputo, p. XX, 28-29 de novembro de 2012. 
à relação com a União Soviética e na explicação dada por Valeriano Ferrão, ex-embaixador de Moçambique nos Estados Unidos da América, para a adoção da ideologia marxista-leninista pelo governo revolucionário ${ }^{19}$. É verdade que nesses aspectos se podem notar sinais de alguma quebra da unidade da narrativa oficial, mas sem levar a fundo uma reflexão sobre o processo. Na nova cena política da contemporaneidade moçambicana, é preciso encontrar fundamento para o lugar que hoje esses homens ocupam. Ainda que não estejam no centro da gestão do Estado, suas vidas gravitam à volta do poder que granjearam e souberam manter, contando efetivamente com o capital simbólico que a participação deles possibilitou. No ato de "contar a sua história", a que se cola a história de Moçambique, esses homens retomam um fio e situam-se no centro da operação que fez nascer o país, buscando resgatar a importância que tiveram ou pensam ter tido.

Sob a perspectiva do exercício memorialístico, a atuação individual de cada um não escapa a padrões registrados em outros contextos. Os anos que sucederam à redemocratização na Argentina, por exemplo, também foram inundados por textos autobiográficos, com os quais os antigos presos, os exilados e muitos dos que tinham vivido diversos modos de tortura e perseguição lançaram seu olhar sobre os chamados anos de chumbo. $O$ alívio gerado pelo fim da ditadura levou a uma valorização dos relatos que, afinal, pintavam com outras cores o passado recente e tenebroso, como se cada movimento de retrospecto contribuísse para uma espécie de exorcismo dos fantasmas que o absurdo tinha espalhado. Passada a explosão emocional, certamente necessária, percebe-se que, em casos assim, embora o objetivo seja trazer o passado à tona, não há como evitar a ponta do presente que se insinua e, não raro, determina os rumos da recordação. Referindo-se aos trabalhos de Paul Ricoeur com a memória, Beatriz Sarlo observa:

O presente da enunciação é o "tempo de base do discurso", porque é presente o momento de se começar a narrar e esse momento fica inscrito na narração. Isso implica o narrador em sua história e a inscreve numa retórica de persuasão (o discurso pertence ao modo persuasivo,

9 Ibidem. 
EXILIUM 1 (2020)

diz Ricoeur). Os relatos testemunhais são "discurso" nesse sentido, porque tem como condição um narrador implicado nos fatos, que não persegue uma verdade externa no momento em que ela é anunciada ${ }^{20}$.

Implicados nos fatos - e é isso que para cada um lhes dá legitimidade -, esses narradores, em alguns casos, explicitam o seu desejo de estar fazendo história, mas ao mesmo tempo ressaltam que não foram orientados pelo compromisso de comprovar a veracidade das suas lembranças, atitude contrária àquela que, como lembra Traverso, mobilizou Leon Trótski na redação do prefácio da História da Revolução Russa e na sua autobiografia. Desconfiando dos artifícios da memória, que não sendo uma "calculadora automática" está mais próxima da "crítica psicanalítica", Trótski não prescindia do confronto com documentos ${ }^{21}$.

A decisão claramente exposta por alguns de seguir o rumo das suas recordações, sendo válida no gênero que escolhem, entra, evidentemente, em colisão com o também exposto desejo de fazer história ${ }^{22}$, deixando patente a sua opção pelo caminho do discurso que tem a sua coesão associada precisamente à força da experiência que, tendo sido vivida, agora é narrada. Graças ao processo de estilização que é próprio do discurso, a narração da memória aciona um potencial argumentativo que provoca a ilusão da captura do real, operação ambicionada para os efeitos persuasivos inscritos entre os sentidos dessa produção que não consegue esconder os sinais de sua dimensão política.

Assumindo o ato de escrever como um dever e como um direito, os homens que atuam na vida do país não trazem para o seu gesto a sombra do ócio que, sabemos, marca o narrador tradicional. Os que escreveram essas obras não estão retirados, não abriram mão da participação na vida pública, continuando, pois, a operar, de acordo com a sua capacidade, na vida do país. E, realmente, na composição desse

20 SARLO, Beatriz. Tempo presente: cultura da memória e guinada subjetiva. São Paulo: Companhia das Letras; Belo Horizonte: Ed. da UFMG, 2007. p. 49.

21 TRAVERSO, Enzo. Melancolia de esquerda: marxismo, história e memória. Belo Horizonte-Veneza: a/Editora Âyiné, 2018. p. 136.

22 Constituem exceção os livros de Helder Martins e Aurélio Langa, que se referem a algum trabalho de checagem na redação de seus livros. 
grupo é que podemos notar uma interessante diferença em relação à situação que mais frequentemente tem gerado essa movimentação do testemunho e da autobiografia. Na Argentina, já referida aqui, o coro que impõe traduz uma ruptura do silêncio imposto pela ordem ditatorial. Após a derrota do regime militar, aqueles que tinham sido silenciados assumem a palavra e oferecem, com todas as questões inerentes ao primado da subjetividade, outras versões para a história oficial daqueles anos. Em Moçambique, vamos verificar a emergência da voz de quem esteve no núcleo da formulação da história oficial. Seus textos vêm agora reiterar o que estava lavrado na grande narrativa. E vêm com a marca da autoridade, não só porque estão ancorados na experiência, mas também porque trazem o timbre da autoridade que eles carregam: entre os autores, temos vários ex-ministros, generais, antigos embaixadores, membros do Bureau Político, uma constelação de primeira grandeza sagrada pelo "roteiro da libertação".

Examinando o repertório produzido, temos, pois, dois dados a merecer registro: além da confirmação da hegemonia dos guerrilheiros sobre aqueles que participaram de outra forma na luta pela independência, entre os quais os militantes que, presos no começo da insurreição, não puderam responder à convocação da luta armada ${ }^{23}$, percebemos a reduzida presença da mulher. Malgrado o anúncio de fim da opressão imposta às mulheres no discurso da libertação, a subjetividade que, assumidamente, conduz o esforço de redesenhar esse tempo que antecedeu a transformação histórica não se mostrou fecunda na captação da sua presença. 0 silêncio marcante no discurso histórico é corroborado pelo exercício da memória, mantendo-a no máximo como coadjuvante de ações de relevo. Como exceções que estão longe de reduzir o tamanho dos problemas, podemos referir o capítulo "A mulher moçambicana emancipada / que traz o povo em seu coração" ${ }^{24}$, de duas páginas, dedicado por Óscar Monteiro em De todos se faz um país, e a participação

23 Em cerca de duas dezenas de livros editados entre os anos 2001 e 2015, constam apenas dois assinados por ex-presos políticos: Memórias da luta clandestina, de Matias Mboa, Memórias de um combatente da causa: $O$ passado que levou o verso da minha vida, de Aurélio Langa.

24 Versos do Hino da Mulher Moçambicana, de Salomão Manhiça. 
de Marina Pachinuapa no volume $A$ vida do casal Pachinuapa. Estamos, indiscutivelmente, diante de um dos silêncios de grande significado nessa produção que afırma pretender preencher lacunas e dar a conhecer aspectos que os moçambicanos precisam conhecer.

Considerando os espaços que as questões de gênero vêm ganhando, inclusive nos debates em Moçambique, com o impulso dado por intelectuais e ativistas do e no país, essa parcimônia na discussão de eventos decorridos no interior da luta, além da própria falta do sujeito feminino, é um dado a merecer atenção. Outro silêncio, contudo, parece mais significativo porque atinge em cheio a composição do grupo que escreve. Trata-se da ausência de reflexão acerca do presente em que eles se situam e que a sua atuação, no mínimo, ajudou a moldar. A virada neoliberal e a consequente concentração de renda instituem uma renúncia aos ideais de justiça social inscritos na cartilha da luta armada e tão alardeados nos discursos dos primeiros anos. A retirada do "popular" do nome do país em 1990 traduzia a adoção de outras formas de condução na economia e na política do Estado. Vivia-se em Moçambique o reflexo de uma tendência internacional, espelhada simbolicamente pela derrubada do Muro de Berlim, em 1989, cujos cacos espalharam-se para muito além do território físico que ocupava.

Sobre a situação internacional e sobre sua projeção no país que fundaram não haveria pouco a dizer. Mas pouco é mencionado. As grandes transformações, que envolvem aspectos pelos quais se fez uma guerra, implicam um novo modelo e a sua gestão permanecerá a cargo não só do mesmo grupo, mas, em muitos casos, dos mesmos indivíduos. A nova direção a ser seguida pelo Partido, formado para assumir o destino coletivo, exprime a demissão dos valores em nome dos quais definiuse uma ordem. Instala-se outra, mas o controle do aparelho estatal é prerrogativa dos "heróis". O capital simbólico abertamente será a base de acumulação de outro capital mais concreto. Ao ignorar as mudanças que representam uma derrota do projeto, embora possam expressar a vitória de alguns setores, essas memórias revelam contradições que são apagadas, como se assim se pudesse colocar fora do debate as suas consequências para o povo em nome do qual lutaram e a quem parecem destinar as suas lembranças. 
Nesse suposto corte pode estar também a explicação para o distanciamento em relação ao cenário internacional, muito pouco discutido nesses textos. Reina nessa produção um certo isolamento, como se os acontecimentos nacionais não fossem influenciados por alianças, adesões, avanços e recuos no campo das relações com o exterior. Construindo uma área de fechamento, os autores revelam-se refratários inclusive à grande mudança que, no final dos anos 1980, abateu a esquerda, área político-ideológica em que estava enquadrado o projeto socialista em que o seu partido apostou. A dissolução da União Soviética e, consequentemente, da polarização que motivava a Guerra Fria não são objetos da sua atenção, isto é, o sentimento de derrota que tomou conta dos seus aliados parece não os alcançar.

Como uma das mais fortes marcas desse nosso tempo, para Traverso, o espectro da melancolia, que é uma das faces do fim das utopias que atravessaram o século XX e orientaram as lutas anticoloniais, cobre os que estiveram em alguma trincheira contra o capitalismo e sonharam com um mundo menos injusto. Sua análise rigorosa das transformações envolve a percepção do passado e o "desaparecimento de toda uma representação do século XX"25, e faz emergir um sentimento de perda que, mesclando dor e luto, não prescinde da consciência. $O$ historiador vai além e pondera:

Mais do que um regime ou uma ideologia, o objeto perdido pode ser a luta como experiência histórica que suscita lembranças e emoções, a despeito de seu caráter frágil, precário e efêmero. Nessa perspectiva, melancolia significa memória e consciência das potencialidades do passado: uma fidelidade às promessas de emancipação revolucionárias, não suas consequências ${ }^{26}$.

Presente em vários gêneros textuais, a melancolia apresenta-se como uma característica forte das modalidades que fazem da memória uma fonte de fatos e de sentidos. Nos escritos que surgem após as grandes crises, que nascem da ruptura e/ou da recuperação de um tempo

25 TRAVERSO, Enzo. Melancolia de esquerda: marxismo, história e memória. Belo Horizonte-Veneza: a/Editora Âyiné, 2018. p. 29.

26 Ibidem, p. 131. 
identificado com a normalidade, ao tonalizar as imagens e modular o ritmo, a melancolia se insere na perspectiva narrativa e, embora, para a psicanálise, ela, em suas medidas e duração, não coincida propriamente com o luto, de seu terreno se aproxima na relação com o passado que, como disposição mental, tende a operar. Próximas da perda e/ou da ausência, as tintas da melancolia interferem na linguagem e dificultam a linearidade, abrindo o campo para a supressão, para o corte, para as elipses que especulam certa interdição no contato com o plano referencial. Se o sentimento predominante espelha apenas o desejo de consolidar uma épica, como parece evidenciar-se nesse conjunto de biografias, a escrita refuta a dúvida, a incerteza e a hesitação que não raro se insinuam no percurso autobiográfico ${ }^{27}$. 0 desejo de persuadir acerca da verdade de que esses narradores se julgam imbuídos atravessa a relação com o leitor, visto apenas como um simples destinatário do discurso que não pode conquistar o estatuto de história, a despeito da ambição confessada em tantas páginas dessa onda autobiográfica que inunda as livrarias de Moçambique.

Não por acaso, a melancolia que se ausenta da produção memorialística encontra abrigo na literatura contemporânea, projetando na sua um outro tipo de aproximação com a História. 0 desestímulo aos escritores à volta da tematização da luta de libertação nacional não teve o mesmo sucesso e, não se rendendo, a dimensão subversiva da literatura leva ao enfrentamento de outros temas que irromperam da vida nacional. Se a guerra contra o exército colonial constituía uma espécie de tabu, a outra, que se estendeu por dezesseis anos, assumindo diversas configurações, penetrou no imaginário dos escritores e foi tratada por nomes sonantes de Moçambique, como Paulina Chiziane, José Craveirinha e Mia Couto, em textos como Ventos do apocalipse, Babalaze das hienas e Terra Sonâmbula, respectivamente, para ficarmos apenas com três títulos. Em As visitas do Dr. Valdez e Crônica da Rua 513.2, João Paulo Borges Coelho debruça-se sobre as questões que decorrem da passagem de uma

27 Da lista de livros publicados até 2014, apenas em Memórias da luta clandestina, de Matias Mboa, encontramos sinais de angústia na linguagem, podendo ser identificada uma aproximação com a escrita literária, inclusive pela adoção de um personagem como alter ego do autor. 
ordem (a colonial) à outra, instituída no pós-independência. Em ambos os textos, outro sinal de desobediência se manifesta: ao localizar uma parte importante do enredo no espaço urbano (a Beira, no primeiro caso, e Maputo, no segundo), as narrativas efetivam um desvio na valorização de um componente de peso na constituição do binarismo que dominou o universo mental dos atores na luta. A cidade, local de perigo na visão dos guerrilheiros, começa a ser incorporada e a conquistar o seu lugar nesse mundo em transformação. Ao lançar-se pelo território do país, quebrando a hierarquização que fazia do campo o espaço de eleição para a eternização de uma mitologia que o tempo necessariamente desgastou, a literatura moçambicana, assumindo a verticalidade que a melancolia favorece, desvela a força da ficção no processo de "descoberta e interpretação" do país.

0 reconhecimento da energia da literatura não exprime, por si só, a crença na possibilidade de comparar textos movidos por propósitos tão diferentes. A alusão a alguns títulos da produção literária decorre da oportunidade de chamar a atenção para a complexidade dos laços entre memória e história em um país como Moçambique e provocar outros modos de ler essa avalanche autobiográfica que, dado o seu volume e o peso dos seus protagonistas, constitui um fato político e, como tal, precisa ser observada. Pretendendo-se como fontes de uma história que, ao fim e ao cabo, foi sempre contada por eles, essas obras pouco acrescentam ao conhecimento que pretendem enriquecer. A necessidade que sentem de falar não se explica por um hipotético regime de silêncio, porque pertencem, na sua grande maioria, ao grupo que tinha direito à voz, mas a constituição dessa espécie de coro é reveladora da vontade de manter o controle sobre o fato maior da nacionalidade. Como depoimento, esses livros nos ajudam a compreender o que são hoje os seus autores e aquilo que os move, o que não é pouco em face do poder que exerceram e ao qual têm dificuldade de renunciar. Diante da opacidade que a boa intenção não ilumina, a ficção rasga algumas veredas e apresenta-nos outras formas de conhecimento, inclusive pela abordagem do labirinto que liga a memória e a história em uma situação em que o poder quer delinear os contornos do saber. Assumindo a arbitrariedade que esses relatos procuram ocultar, o texto literário pode abrir a discussão, como temos em Rainhas da noite, de João Paulo Borges Coelho. 0 escritor, que 
é historiador e tem se dedicado à compreensão dos mecanismos que vêm interferindo na produção historiográfica moçambicana e dos sutis movimentos da memória, como pudemos referir aqui e nesse romance de 2014, ele, partindo de um caderno de memórias encontrado pelo personagem-narrador, mergulha nas águas insubordinadas que envolvem a conexão entre as brumas do indecifrável passado e o "circo insano do presente" ${ }^{12}$. Para desvelar as variadas maneiras de instrumentalizar o tempo, Borges Coelho questiona os recursos com que tentam capturá-lo e, nesse movimento, procura atingir as linhas que delimitam as modalidades literárias, como enfatiza a leitura sensível e percuciente de Nazir Can:

Nesta narrativa coral que baralha as fronteiras do gênero (diário, crônica, ensaio, romance, romance histórico, romance policial) demarcando gêneros (feminino e masculino), e entrecruza, reavaliando-as, diversas fontes de investigação (caderno de memórias, fotografias, arquivo, testemunha), João Paulo Borges Coelho questiona a hierarquia e a legitimidade dos relatos sobre a passagem do tempo, desempoeira do passado algumas linhas de continuidade com o presente e radicaliza um posicionamento intelectual que, partindo da e celebrando a literatura, faz da discussão sobre a memória e a história sua pedra angular ${ }^{29}$.

Como outros ficcionistas do presente moçambicano, João Paulo Borges Coelho escapa aos limites um tanto asfixiantes de um compromisso com a univocidade e faz do antilusionismo uma ferramenta poderosa para desvelar o céu nebuloso de um país que em tão pouco tempo viveu tantas crises e assistiu a tantas mudanças. Sem poder se ancorar na serenidade de um mirante protegido, a literatura brinca com o projeto de ser verdade e investe mais fortemente na sua capacidade formativa, oferecendo ao mesmo tempo instrumentos com que pode olhar mais profundamente o país. Na desordem produtiva que instala, a literatura moçambicana vai compondo quadros nos quais se espelha o tempo como um tecido invisível. E nos ajuda a compreender também o que nele se borda.

28 COELHO, João Paulo Borges. Rainhas da noite. Lisboa: Caminho, 2013. p. 358.

29 CAN, Nazir. Rainhas da noite. Metamorfoses, Rio de Janeiro, v. 14, n. 2, 2017. Disponível em: $\quad$ https://revistas.ufrj.br/index.php/metamorfoses/article/view/17999/10868. Acesso em: 5 ago. 2020. 


\section{Referências}

CAN, Nazir. Rainhas da noite. Metamorfoses, Rio de Janeiro, v. 14, n. 2, 2017. Disponível em : https://revistas.ufrj.br/index.php/metamorfoses/article/ view/17999/10868. Acesso em: 5 ago. 2020.

CANDIDO, Antonio. Formação da literatura brasileira: Momentos decisivos. 6. ed. Belo Horizonte: Itatiaia, 1981.

CARVALHO, Ruy Duarte de. Actas da Maianga. Lisboa: Cotovia, 2003.

CHISSANO, Joaquim. Vidas, lugares e tempos. Maputo: Texto Editores, 2010. COELHO, João Paulo Borges. E depois de Caliban? As histórias e os caminhos da literatura no Moçambique contemporâneo. In: GALVES, C. et al. ÁfricaBrasil: Caminhos da língua portuguesa. Campinas: Ed. da Unicamp, 2009.

COELHO, João Paulo Borges. Rainhas da noite. Lisboa: Caminho, 2013.

COELHO, João Paulo Borges. Abrir a fábula: Questões de política do passado em Moçambique. Revista Crítica de Ciências Sociais, Coimbra: CES, n. 106, 2015.

COELHO, João Paulo Borges. Política e história contemporânea em Moçambique: dez notas epistemológicas. Revista de História, São Paulo, n. 178, 2019. Disponível em: http://dx.doi.org/10.11606/issn.2316-9141. rh.2019.146896. Acesso em: 5 ago. 2020.

CRUZ E SILVA, Teresa. Memória, história e narrativa: Os desafios da escrita biográfica no contexto da luta nacionalista em Moçambique. Revista Crítica de Ciências Sociais, n. 106, p. 133-152, 2015. Disponível em: http://dx.doi. org/10.4000/rccs.5916. Acesso em: 5 ago. 2020.

FERRÃO, Valeriano. Embaixador nos USA. Maputo: Ndjira, 2007.

GASPARINI, P. Autoficção é o nome de quê? In: NORONHA, Jovita (org.). Ensaios sobre a autoficção. Belo Horizonte: Ed. UFMG, 2014.

HONWANA, Luís Bernardo. A velha casa de madeira e zinco. Maputo: Alcance, 2017. 
LANGA, Aurélio Valente. Memórias de um combatente da luta de libertação: o passado que levou o verso da minha vida. Maputo: JV Editores, 2011.

LE GOFF, J. História e Memória. 7. ed. São Paulo: Ed. Unicamp, 2013.

MARTINS, Helder. Porquê Sakrani?: memórias de um médico de uma guerrilha esquecida. Maputo: Editora Terceiro Milênio, 2001.

MBEMBE, Achille. Crítica da razão negra. 1. ed. Lisboa: Antígona, 2014.

MBOA, Matias. Memórias da luta clandestina. Maputo: Marimbique, 2009.

MOIANE, José Phahlane. Memórias de um guerrilheiro. [s. I.]: King Ngungunhane Institute, 2009.

MONTEIRO, Óscar. De todos se faz um país. Maputo: Associação dos Escritores Moçambicanos, 2012.

NALYAMBIPANO, Salésio. A minha contribuição para a independência e edificação do Estado moçambicano: memórias de um general da linha da frente. Maputo: CPHLLN, 2013.

NORONHA, Jovita (org.). Ensaios sobre a autoficção. Tradução de Maria Inês Coimbra Guedes. Belo Horizonte: Ed. da UFMG, 2014.

PACHINUAPA, Raimundo; PACHINUAPA, Marina. A vida do casal Pachinuapa. Maputo: Edição do Autor, 2009.

PELEMBE, João Facitela. Lutei pela pátria: memórias de um combatente da luta de libertação nacional. Maputo: Edição do Autor, 2012.

RICOEUR, Paul. A memória, a história, o esquecimento. Campinas: Ed. da Unicamp, 2007.

ROSAS, Fernando. História e memória. Lisboa: Tinta da China, 2016.

SOUTO, Amélia Neves. História, memória e identidade na história da FRELIMO/ Moçambique. Conferência Internacional: os intelectuais africanos face aos desafios do século XXI. Em memória de Ruth First (1925-1982). Anais... Maputo, 28-29 de novembro de 2012. 
SOUTO, Amélia Neves. Memory and Identity in the History of FRELIMO: Some Research Themes. Kronos, n. 39, p. 280-296, 2013.

SARLO, Beatriz. Tempo presente: cultura da memória e guinada subjetiva. São Paulo: Companhia das Letras; Belo Horizonte: Ed. da UFMG, 2007.

TRAVERSO, Enzo. Melancolia de esquerda: marxismo, história e memória. Belo Horizonte-Veneza: a/Editora Âyiné, 2018.

VELOSO, Jacinto. Memórias em voo rasante. Maputo: António José Correia Paulo, 2006.

VIEIRA, Sérgio. Participei, por isso testemunho. Maputo: Ndjira, 2010. 